Larry Kahn BSC (med), MB CHB

\title{
Neuropathies masquerading as an epidural complication
}

Purpose: The purpose of this report is to emphasise the role of the Acute Pain Service in managing local anaesthetic epidural infusions for postoperative pain management, the importance of vigilant monitoring, and to offer some guidelines to using local anaesthetic epidural infusions.

Clinical features: A 34-yr-old man with long-standing insulin dependent diabetes mellitus underwent a total proctocolectomy for inflammatory bowel disease. A T9-10 epidural catheter was placed prior to induction of general anaesthesia. Postoperatively, a continuous epidural infusion of fentany/bupivacaine was used for postoperative pain management. Total lithotomy time was four hours. On day four he was noted to have complete right sided femoral and left sided lateral femoral cutaneous nerve of thigh neuropathies. A computerised tomography scan and a magnetic resonance imaging excluded a central lesion. Electromyelography confirmed peripheral nerve injuries.

Conclusion: This patient's neurological deficits were not due to the epidural analgesia. However, epidural infusion of local anaesthetic caused a delay in recognising a potential neurological complication. When using local anaesthetic epidural infusions, it is important to exclude other causes of motor block before attributing it to the local anaesthetic.

Objectif : Ce compte rendu vise à souligner le rôle d'un service de gestion de la douleur aiguë sous l'aspect de la prise en charge des perfusions épidurales d'anesthésiques locaux administrées pour le traitement de la douleur postopératoire; rappeler l'importance d'une surveillance étroite : proposer des lignes de conduite sur l'utilisation des perfusions épidurales d'anesthésiques locaux.

Éléments cliniques : Un homme de 34 ans souffrant d'un diabète insulino-dépendant de longue date subissait une colectomie totale pour une maladie inflammatoire intestinale. Un cathéter épidural était installé a T9-10 avant l'induction de l'anesthésie générale. En postopératoire, une perfusion continue de fentany/bupivacaine était mise en marche pour soulager la douleur postopératoire. La position de lithotomie avait été maintenue pendant quatre heures. Le quatrième jour, on décelait des neuropathies graves du nerf fémoral droit et du nerf férnorocutané latéral gauche de la cuisse. La tomographie informatisée et l'imagerie par résonance magnétique éliminaient la présence d'une lésion centrale. L'électromyographie confirmait que les lésions nerveuses étaient périphériques.

Conclusion : Dans le cas présent, les déficits neurologiques n'étaient pas en rapport avec l'analgésie épidurale. Cependant, la perfusion épidurale d'un anesthésique local a retardé le diagnostic d'une complication neurologique. Avec les perfusions épidurales d'anesthésiques locaux, il est important d'éliminer les autres causes de bloc moteur avant de les attribuer aux anesthésiques.

From the Acute Pain Service, Department of Anesthesia, St. Joseph's Hospital, 50 Charlton Ave E, Hamilton, Onrario, L8N 4A6, Canada. Phone: 905 522-1155 Ext. 3853; E-mail: kahn|@ifhs.memaster.ca

Accepted for publication Nopember 30, 1996. 
$\mathrm{T}$ HE popularity of epidural infusions with local anaesthetic mixtures, for postoperative analgesia, is increasing in Canada. ${ }^{1}$ We, therefore, expect to see more cases experiencing complications related to this technique. The following case report illustrates an unusual neurological complication, unrelated to an epidural catheter. It emphasises the importance of careful monitoring and neurological examination to exclude more serious and reversible epidural related complications.

\section{Case Report}

A 34-yr-old man with insulin dependent diabetes mellitus since the age of 20 , underwent total proctocolectomy for inflammatory bowel disease. $\mathrm{He}$ was a non-smoker, weighed $82 \mathrm{~kg}$, and was $181 \mathrm{~cm}$ tall. His Body Mass Index (BMI.) was 25. His diabetes was well controlled and there was no pre-operative evidence of neurological deficits or other end-organ involvement.

Prior to induction of general anesthesia, an epidural catheter was inserted at the T9-10 interspace, using a paramedian approach with a loss of resistance technique. This was an uneventful insertion: there was no paraesthesia; a test dose of $3 \mathrm{ml}$ lidocaine $1.5 \%$ with 1:200 000 epinephrine confirmed that the catheter was not intrathecal nor intravenous. General anaesthesia was induced with $150 \mathrm{mg}$ propofol and $40 \mathrm{mg}$ atracurium was used as a muscle relaxant to facilitate tracheal intubation. Isoflurane $0.5-1 \%$ in air/oxygen mixture and epidural bupivacaine $0.5 \%$ plain were used to maintain anaesthesia. An atracurium infusion, $5-10 \mu \mathrm{g} \cdot \mathrm{kg}^{-1} \cdot \mathrm{min}^{-1}$ titrated against the train of four response of a peripheral nerve stimulator, provided neuromuscular paralysis. All pressure points were protected with foam padding. There were no unusual intraoperative events. The patient was in the lithotomy position for four hours. At the end of the procedure the neuromuscular blockade was reversed with neostigmine and glycopyrrolate, and the trachea was extubated. The parient was transferred to the post anaesthesia recovery room (PARR) awake and comfortable.

A continuous epidural infusion of bupivacaine $0.125 \%$ and $5 \mu \mathrm{g} \cdot \mathrm{ml}^{-1}$ fentanyl was started in PARR at a rate of $10 \mathrm{ml} \cdot \mathrm{hr}^{-1}$. The patient was transferred to the surgical floor, where his pain management was taken over by the Acute Pain Service (APS).

On the second postoperative day he complained of some heaviness in his lower limbs. His epidural infusion was therefore reduced to $6 \mathrm{ml} \cdot \mathrm{hr}^{-1}$, on the assumption that the motor block was due to the epidural bupivacaine. A detailed neurological examination was not recorded. However, after a few hours he began to com- plain of incisional pain. His leg heaviness had not resolved, but because his pain had returned, he received a $5 \mathrm{ml}$ bolus of the same epidural mixture, and his infusion was reset to the original rate. The patient's pain was relieved, but his lower limb heaviness persisted. Once again the lower limb heaviness was assumed to be secondary to epidural bupivacaine. The following day, the APS had a similar experience with him: his lower limb heaviness persisted, the epidural infusion was therefore reduced, resulting in his pain returning. There was no resolution of the limb heaviness, but because he had incisional pain, the epidural infusion rate was again increased. On postoperative day three, his epidural catheter was discontinued. It was only on postoperative day four, when he still complained of heavy legs, that a thorough neurological examination was performed. $\mathrm{He}$ had lack of sensation to pinprick in the distribution of the right femoral nerve and the left lateral femoral cutaneous nerve of thigh. Bilateral hip flexion and left knee extension were normal. Knee extension on the right leg was weak. The right knee reflex was absent, but the ankle and plantar reflexes were normal bilaterally. Perineal sensation and reflexes were normal. There was no tenderness nor swelling over the site of the epidural insertion.

At this point, neurological and neurosurgical consultations were requested. A computerised tomographic scan (CT) and magnetic resonance imaging (MRI) of the thoracolumbar spine were normal, excluding a central lesion. Electromyelographic studies three months later confirmed the lesions to be peripheral nerve injuries at the level of the right femoral nerve and the left lateral femoral cutaneous nerve of thigh. At six months, he had minimal resolution of his femoral neuropathy and required a leg brace to aid walking.

\section{Discussion}

Although this patient received epidural analgesia for postoperative pain, his neurological deficits were unrelated to it. However, the epidural infusion of local anaesthetic did cause a delay in recognising a potential neurological complication.

In a recent survey of acute pain practice in Canada, ${ }^{1}$ $12 \%$ of surveyed hospitals used continuous epidural infusions with combined local anaesthetic-opioid mixtures, on regular wards, for pain management. There are numerous reports of the safety and efficacy of this technique. ${ }^{2-4}$ The most common problem is undesirable motor blockade. This may hamper ambulation or mask a more serious complication such as neurological damage or epidural mass.

A mid-dermatomal thoracic epidural insertion was chosen to allow local anaesthetic and lipophilic opioid 
to be used more effectively. 5 The segmental block obtained with the local anaesthetic at this level has been associated with a lower incidence of motor blocks in the lower limbs ${ }^{6}$ and possible acceleration of bowel recovery. ${ }^{7-10}$ Lipophilic opioids such as fentanyl are probably more effective when deposited at the site of action. ${ }^{5}$ Ironically, this patient had persistent lower limb heaviness despite a thoracic epidural, and perhaps this should have alerted the APS to a possible complication.

Careful neurological assessment localised the site of the lesion. Hip flexion is provided mainly by the iliopsoas muscle, which is innervated by the nerve to iliopsoas. This nerve arises proximal to the femoral nerve in the lumbar plexus. The quadriceps muscle group is innervated by the femoral nerve, which also arises from the lumbar plexus. Preservation of hip flexion, loss of quadriceps power and a sensory deficit in the area supplied by the femoral nerve, implies that the lesion must be distal to the nerve to iliopsoas. It is, therefore, unlikely that this lesion could have resulted directly from an epidural catheter or infusion. This patients clinical picture was atypical in that he had bilateral neurological deficits: right femoral and left lateral femoral cutaneous nerve of thigh neuropathies.

In the more acute situation it is imperative to exclude extrinsic cord compression from an epidural mass. A CT scan and MRI were performed to exclude a central lesion. It is well known that urgent neurosurgical decompression before the onset of a complete sensorimotor deficit ${ }^{11}$ or within eight hours of onset ${ }^{12}$ can reverse the neurological lesion

There have been numerous reports ${ }^{13-15}$ of femoral neuropathy following various surgical procedures such as abdominal hysterectomy, inguinal hernia repair, aortic aneurysm repair, prostatectomy and total hip replacements. The severity of the neuropathy depended on the type of surgery. This ranged from mild sensory loss, to complete motor neuropathy with no recovery. The reported incidence is from 1 in $3608^{13}$ to $11 \%$ in abdominal hysterectomies when a selfretaining retractor was used. ${ }^{14}$ The pathophysiology ${ }^{15}$ of nerve injury may be secondary to compression, stretch, transection, iliopsoas haematoma or ischaemia. Prolonged lithotomy positioning has been associated with femoral neuropathy. Warner et al. ${ }^{13}$ in a retrospective review of 198,461 patients over a $35 \mathrm{yr}$ period who underwent surgery in the lithotomy position, found four patients with isolated femoral nerve palsies. Anaesthetic technique was not an associated risk factor. Lithotomy $>$ four hours, smoking in the perioperative period and a BMI of $\leq 20$ were found to have independent value for predicting the development of a motor neuropathy. When multivariate analy- sis was applied, diabetes was not strongly predictive of motor neuropathy after adjusting for other risk factors. Brasch $e t a l .^{14}$ reported a series of femoral neuropathies following the use of self-retaining retractors. These were not used in this case.

Frequent cardio-respiratory monitoring and an assessment of lower limb power in patients recciving continuous local anaesthetic epidural infusions, should be mandatory. Nurse monitoring protocols should include assessment of motor blockade. The APS or a designated individual should be contacted ${ }^{16}$ when patients develop a motor block. Individuals managing these patients should have a thorough understanding of the neuroanatomy and be able to perform an appropriate neurological assessment. If local anaesthetic epidural infusions are used, other causes of motor block (epidural mass, intrathecal catheter) should be excluded if the block does not recede on manipulating the epidural infusion rate.

Motor blockade with continuous infusions of local anaesthetics via lumbar epidural catheters, may impede ambulation and increase the work load for an APS. Our APS has restricted the use of continuous local anacsthetic epidural infusions to the following situations:

a) Lumbar epidural catheters for major lower limb orthopaedic procedures.

b) Thoracic epidural catheters because of the lower incidence of lower limb motor blocks. ${ }^{5,6}$

c) Lower limb vascular surgery because of a possible reduction in graft occlusion. ${ }^{17,18}$

d) Specific pain problems not responding to epidural opioids alone.

This approach has reduced the incidence of lower limb motor blocks, lessened the work load in managing these patients, encouraged earlier ambulation, and hopefully reduced the risk of masking potentially serious and reversible epidural complications.

\section{Conclusion}

It is likely that this patient's neuropathies were due to the lengthy lithotomy position ${ }^{13}$ and not the epidural analgesia. However, the diagnosis was delayed because the motor block was attributed to the epidural local anaesthetic. Monitoring of patients receiving epidural infusions with local anaesthetic should include an assessment of lower limb motor function. Other causes of motor blockade should be excluded before attributing it to the epidural local anaesthetic, otherwise serious reversible lesions may be missed. Selective use of epidural infusions with local anaesthetic may lower the incidence of motor blocks, thus reducing this complication. 


\section{Acknowledgments}

Thanks to Drs. J. McChesney, L. Chiu, D Sheinbaum for reviewing the script.

\section{References}

1 Zimmerman D L, Stewart J. Postoperative pain management and Acute Pain Service activity in Canada. Can J Anaesth 1993; 40: 568-75.

2 Lee $A$, Simpson D, Whitfield $A$, Scott DB. Postoperative analgesia by continuous extradural infusion of bupivacaine and diamorphine. Br J Anaesth 1988; 60: 845-50.

3 Flanagan $H L$, Fanciullo $G$, Walsh D, Ferrante FM. Safety and efficacy of post-operative continuous epidural narcotic-local anesthetic infusions on surgical floors. Anesthesiology 1993; 79: A794.

4 Schug $S A$, Cann J, Fry RA. Continuous epidural infusion of a bupivacaine-fentanyl-mixture for postoperative pain relief: a follow-up of 425 patients. Reg Anesth 1992; 17: 3S77.

5 Liu S, Carpenter RL, Neal JM. Epidural anesthesia and analgesia. Their role in postoperative outcome. Anesthesiology 1995; 82: 1474-506.

6 Moiniche S, Hjortsø N-C, Blemmer T, Dabl JB, Keblet $H$. Blood pressure and heart rate during orthostatic stress and walking with continuous postoperative thoracic epidural bupivacaine/morphine. Acta Anaesthesiol Scand 1993; 37: 65-9.

7 Scratcherd T, Grundy $D$. The physiology of intestinal motility and secretion. Br J Anaesth 1984; 56: 3-18.

8 Udassin R, Eimerl D, Schiffman J, Haskel $\Upsilon$. Epidural anesthesia accelerates the recovery of postischemic bowel motilty in the rat. Anesthesiology 1994; 80: 832-6.

9 Bredtmann RD, Herden HN, Teichmann W, et al. Epidural analgesia in colonic surgery: results of a randomized prospective study. Br J Surg 1990; 77: 638-42.

10 Schnitzler $M$, Kilbride $M$ J, Senagore $M$. Effect of epidural analgesia on colorectal anastomotic healing and colonic motility. Reg Anesth 1992; 17: 143-7.

11 Mattle H, Sieb JP, Rohner M, Mumentbaler $M$. Nontraumatic spinal epidural and subdural hematomas. Neurology 1987; 37: 1351-6.

12 Schmidt $A$. Nolte $H$. Subdural and epidural haematomas following spinal, epidural or caudal anaesthesia. (German) Anaesthesist 1992; 41: 276-84.

13 Warner $M A$, Martin JT, Schroeder DR, Offord $K P$, Chute CG. Lower-extremity motor neuropathy associated with surgery performed on patients in a lithotomy position. Anesthesiolgy 1994; 81: 6-12.

14 Brasch RC, Bufo AJ, Kreienberg PF, Jobnson GP. Femoral neuropathy secondary to the use of a self-retaining retractor. Dis Colon Rectum 1995; 38: 1115-8.

15 Al Hakim M, Katirji MB. Femoral mononeuropathy induced hv the lithotomv nosition: a report of 5 cases with a review of the literature. Muscle Nerve 1993; 16 : 891-5.

16 A report by the ASA Task Force on Pain Management, Acute Pain Section. Practice guidelines for Acute Pain Management in the perioperative setting. Anesthesiology 1995; 82: 1071-81.

17 Christopherson R, Beattie C, Frank SM, et al. Perioperative morbidity in patients randomized to epidural or general anesthesia for lower extremity vascular surgery. Anesthesiology 1993; 79: 422-34.

18 Tuman KJ, McCarthy RJ, March RJ,DeLaria GA, Patel $R V$, Ivankovich $A D$. Effects of epidural anesthesia and analgesia on coagulation and outcome after major vascular surgery. Anesth Analg 1991; 73: 696-704. 